Revista Científica ANAP Brasil

ISSN 1984-3240 - Volume 13, número 30, 2020

\title{
Estudos sobre as Motocicletas no Trânsito Metropolitano
}

Study On Motorcycles In Metropolitan Transit

Estudio Sobre Motocicletas En Tránsito Metropolitano

Marina Leite de Barros Baltar Professora Mestre, UFMT, Brasil. mabaltar@gmail.com

\section{Luana Fagundes Peletti}

Graduanda, UFMT, Brasil. Luanapeletti1@gmail.com

Matheus da Silva Graduando, UFMT, Brasil. matsilva09@outlook.com 


\title{
Revista Científica ANAP Brasil
}

\author{
ISSN 1984-3240 - Volume 13, número 30, 2020
}

\section{INTRODUÇÃO}

De acordo com Biffe et al. (2017), os acidentes de trânsito cresceram vertiginosamente na década de 2000, ocasionando um impacto socioeconômico. Mais de 1,25 milhões de pessoas perderam suas vidas no trânsito no período de 2007 a 2013, e quase 50 milhões ficaram com algum tipo de sequela devido aos acidentes de trânsito. A Organização Mundial da Saúde (OMS) afirma que, em 2015, esses acidentes representaram a primeira causa de mortes na faixa etária de 15 a 29 anos, com um custo global estimado em 518 bilhões de dólares para o ano de 2015.

Devido as ocorrências de trânsito que são apresentadas anualmente pela OMS, realizou-se um estudo exploratório "As motocicletas no trânsito metropolitano", que visa elaborar um panorama de como se encontra a situação do trânsito na área conurbada "Cuiabá-Várzea Grande".

Atualmente o crescimento desenfreado das grandes cidades o qual traz consigo uma necessidade por gestão e planejamento urbano, as quais nem sempre conseguem acompanhar esse ritmo de expansão e culminam no surgimento de problemas sócio espaciais que comprometem a qualidade de vida nos centros urbanos. Conforme cita Costa (2003), "o crescimento acelerado das cidades e as transformações que estas vêm passando originam a uma nova forma de ação social, na qual o ordenamento urbano é considerado como um exercício de controle dos espaços urbanos", reafirmando a necessidade de um planejamento estratégico dos municípios.

Um dos principais problemas recorrentes dessa expansão são os Acidentes de Trânsito (AT), que por mais variados que sejam seus motivos ocorrem com muita frequência comprometendo a segurança de toda a população. Os impactos gerados por esses AT's influenciam de forma negativa no cotidiano e na qualidade de vida dentro de um município, gerando problemas não só para os envolvidos, mas também custos sociais e geram gastos com saúde ao governo.

Segundo Noronha e Morais (2011) é importante que se considere as diferentes categorias de veículos e a proporção de crescimento da frota ao longo do tempo. Os acidentes que envolvem motocicletas, em especial, provocam, comparativamente a outros veículos, um maior número de acidentes. Entende-se então que os acidentes com motocicleta venham a ser mais frequentes e envolvem um perigo maior por conta de fatores como a proteção inadequada do usuário, uma maior vulnerabilidade de seus ocupantes e o comportamento inadequado dos motoristas no perímetro urbano.

Com base nisso, esse estudo busca analisar dados secundários relacionados ao trânsito do estado de Mato Grosso para auxiliar nas medidas de prevenção de acidentes e conscientizar as pessoas quanto a importância da educação no trânsito.

Para isso utiliza-se neste trabalho um banco de dados fornecidos pela Secretaria de Mobilidade Urbana, o qual apresenta análises estatísticas do trânsito em Mato Grosso através de bases secundárias, especialmente na capital Cuiabá. Além disso, realizou-se uma pesquisa em campo para compreender o perfil dos motociclistas da região e entender sua percepção sobre o trânsito na região. 


\title{
Revista Científica ANAP Brasil
}

\author{
ISSN 1984-3240 - Volume 13, número 30, 2020
}

\section{OBJETIVOS}

- Analisar base de dados já existentes relacionadas ao trânsito de Mato Grosso, com ênfase em Cuiabá, para que seja possível orientar e conscientizar seus leitores sobre a importância de serem levantadas as problemáticas nessa área e achar a busca por soluções coletivas;

- Estudar especificamente os motociclistas, seu perfil social, sua forma de condução e o envolvimento em acidentes.

\section{METODOLOGIA}

O estudo se divide em duas partes, Erro! Fonte de referência não encontrada., conforme a primeira é uma compilação de bancos de dados com análises estatísticas do trânsito em Mato Grosso através de bases secundárias, especialmente na capital Cuiabá. Já a segunda parte do trabalho compreende em uma pesquisa realizada em campo para compreender o perfil dos motociclistas da região e entender sua percepção sobre o trânsito na região.

Figura 1: Metodologia adotada

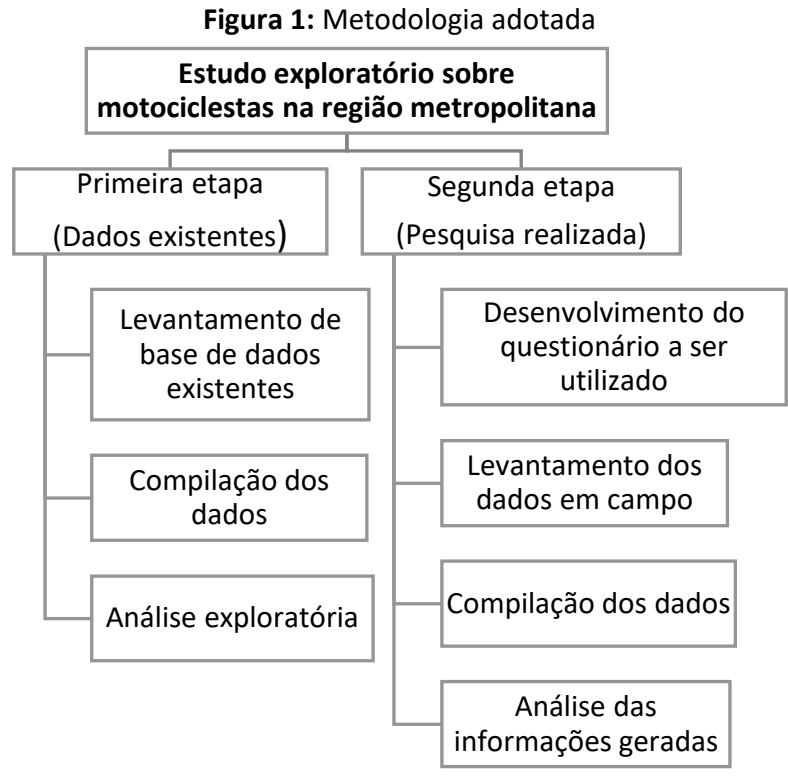

Fonte: AUTORES, 2020.

\section{RESULTADOS}

Análise dos Dados no Estado de Mato Grosso

Analisando os dados obtidos do Estado de Mato grosso, podemos observar a Tabela 1, e percebe-se que do ano de 2016 para 2018 houve uma diminuição de aproximadamente 14,3\% no número de acidentes totais, resultados provenientes das diversas campanhas de conscientização que vêm ocorrendo nos últimos anos. De modo contraditório o número de acidentes fatais do ano de 2017 para 2018 voltou a crescer, além disso a relação entre os acidentes totais e os acidentes fatais aumentou, o que implica um aumento no número de óbitos apesar da queda no número total relacionado aos anos anteriores 


\title{
Revista Científica ANAP Brasil
}

\author{
ISSN 1984-3240 - Volume 13, número 30, 2020
}

Tabela 1: Acidentes de Trânsito com vítimas nos anos de 2016 a 2018

\begin{tabular}{|c|c|c|c|c|c|}
\hline Ano & $\begin{array}{c}\text { Quantidade } \\
\text { total }\end{array}$ & Fatais & Relação & Não fatais & Relação \\
\hline 2016 & 8.546 & 701 & $8,2 \%$ & 7.845 & $91,8 \%$ \\
\hline 2017 & 8.407 & 586 & $7,0 \%$ & 7.821 & $93,0 \%$ \\
\hline 2018 & 7.312 & 641 & $8,7 \%$ & 6.671 & $91,3 \%$ \\
\hline
\end{tabular}

Fonte: SINESP - SESP/MT

Quanto ao sexo da vítima, homens obtiveram uma redução no valor total e nas fatalidades, em quanto as mulheres tiveram um aumento apenas no valor total (o que pode ser justificado pelo número crescente de mulheres que vem adquirindo a Carteira Nacional de Habilitação - CNH nos últimos anos).

Confirma-se também que os acidentes com vítimas estão relacionados em maior quantidade a jovens de 18 a 24 anos (27,0\% em 2018) e adultos de 35 a 64 anos (33,9\% em 2018, justificado pela maior abrangência no intervalo de idade analisado), além de ocorrerem principalmente no período noturno (38,6\% em 2018) conforme observado nas Tabelas 2 e 3.

Tabela 2: Acidentes de Trânsito com Vítimas por Faixa Etária

\begin{tabular}{|c|c|c|c|c|c|c|c|c|}
\hline \multirow[b]{2}{*}{ Ano } & \multicolumn{8}{|c|}{ Faixa Etária (Anos) } \\
\hline & $0-11$ & $12-17$ & $18-24$ & $25-29$ & $30-34$ & $35-64$ & $65+$ & $\begin{array}{c}\text { Não } \\
\text { informado }\end{array}$ \\
\hline 2016 & $10,8 \%$ & $4,2 \%$ & $18,7 \%$ & $12,4 \%$ & $12,5 \%$ & $38,3 \%$ & $3,2 \%$ & $0,1 \%$ \\
\hline 2017 & $3,7 \%$ & $4,0 \%$ & $20,7 \%$ & $13,0 \%$ & $12,5 \%$ & $40,4 \%$ & $3,5 \%$ & $2,2 \%$ \\
\hline 2018 & $3,9 \%$ & $4,9 \%$ & $27,0 \%$ & $14,9 \%$ & $12,2 \%$ & $33,9 \%$ & $3,1 \%$ & $0,1 \%$ \\
\hline
\end{tabular}
Fonte: SESP/MT

Tabela 3: Acidentes de Trânsito com vítimas por faixa de horário de 2016 a 2018

\begin{tabular}{|c|c|c|c|}
\hline Ano & Matutino & Vespertino & Noturno \\
\hline $\mathbf{2 0 1 6}$ & $26,7 \%$ & $39,6 \%$ & $33,7 \%$ \\
\hline $\mathbf{2 0 1 7}$ & $28,4 \%$ & $33,0 \%$ & $38,6 \%$ \\
\hline $\mathbf{2 0 1 8}$ & $26,4 \%$ & $35,0 \%$ & $38,6 \%$ \\
\hline
\end{tabular}

Fonte: SEMOB/MT

Contudo, a observação dos dados de trânsito do Município de Cuiabá, mostra que vem constantemente aumentando sua frota veicular, o que está diretamente relacionado a um aumento no número de acidentes locais (+20,0\% de 2017 para 2018), contanto também com um total de 1.304.789 motoristas habilitados de ambos os sexos para o mesmo ano.

Tratando-se dos acidentes fatais em específico sua grande maioria ocorre com vítimas de 18 a 25 anos (25,9\% em 2018), na posição de motorista $(66,7 \%$ em 2018$)$ e com a utilização de motocicletas (53,7\% em 2018), causados em sua maior parte pela falta da CNH e o excesso de velocidade.

Ao observar os dados levantados pela pesquisa realizada em campo observa-se na Tabela 4 que a maioria dos motociclistas são do sexo masculino (67\%) e além disso tem como grau de escolaridade o ensino médio completo (58\%), como observamos na Tabela 5. 


\section{Revista Científica ANAP Brasil}

ISSN 1984-3240 - Volume 13, número 30, 2020

Tabela 4: Distribuição do sexo dos pesquisados

\begin{tabular}{|c|c|}
\hline \multicolumn{2}{|c|}{ Tabela 4: Distribuição do sexo dos pesquisados } \\
\hline Sexo & Porcentagem ${ }^{1}$ \\
\hline Masculino & $67 \%$ \\
\hline Feminino & $32 \%$ \\
\hline Trans. & $1 \%$ \\
\hline
\end{tabular}

Fonte: Autores, 2020.

Tabela 5: Nível de escolaridade dos entrevistados

\begin{tabular}{|c|c|}
\hline Grau de escolaridade $^{2}$ & Porcentagem \\
\hline Fundamental I & $3 \%$ \\
\hline Fundamental C & $9 \%$ \\
\hline Médio I & $1 \%$ \\
\hline Médio C & $58 \%$ \\
\hline Superior I & $13 \%$ \\
\hline Superior C & $14 \%$ \\
\hline Técnico & $1 \%$ \\
\hline Analfabeto & $1 \%$ \\
\hline
\end{tabular}

Fonte: pesquisa de campo.

Os dados coletados apontam para um envolvimento maior do sexo masculino em acidentes graves em comparação com o feminino. Há um predomínio de vítimas do sexo masculino em vários estudos, realizados em diferentes cidades brasileiras. Conforme as amostras de dados apresentados, o fato de o sexo masculino ser as maiores vítimas no trânsito, pode ser devido ao comportamento social e cultural de maior exposição aos riscos dessas ocorrências, como velocidade excessiva, maior consumo de álcool e agressividade no trânsito.

Nos estudos realizados pela Secretaria de Mobilidade Urbana (SEMOB) no Estado de Mato Grosso e no munícipio de Cuiabá, é mostrado que as maiores vítimas de acidentes de trânsito são os jovens, esse fato ocorre devido ao comportamento impulsivo e destemido intrínseco à idade. Ademais, que entra dentro dessas estatísticas o abuso de álcool e/ou drogas utilizado por esse grupo etário, que subestima os riscos e conduz seus veículos de forma arriscada e desrespeitando as regras de trânsito.

Em relação ao grau de escolaridade, observa-se que este influencia no índice de envolvimento em acidentes graves, quanto menor o grau de escolaridade, maior a porcentagem de motoristas que já se envolveram em acidentes. Os condutores com nível superior incompleto ou completo são os que menos sofreram acidente, observe Gráfico1.

\footnotetext{
${ }^{1}$ Dados da porcentagem foram arredondados.
}

2 "I" para incompleto e " $C$ " para completo. 


\section{Revista Científica ANAP Brasil}

ISSN 1984-3240 - Volume 13, número 30, 2020

Gráfico 1: Proporção de envolvimento em acidente grave por nível de escolaridade

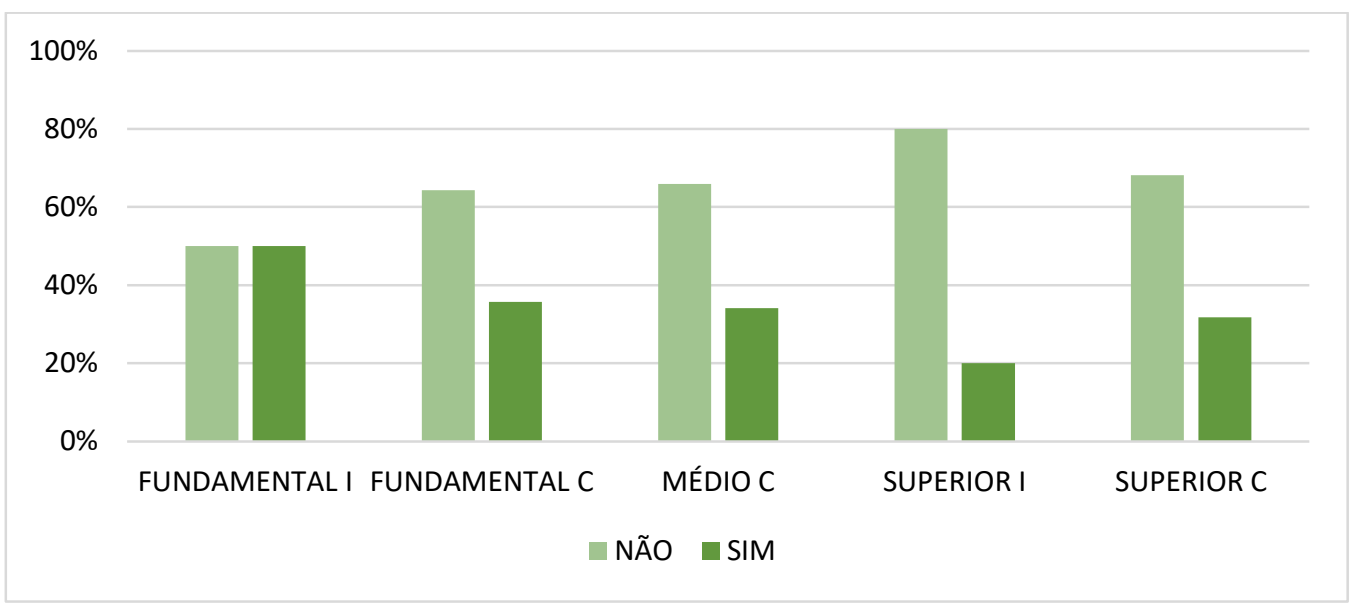

Fonte: AUTORES, 2020.

Além disso, com o questionário, obteve-se que $67 \%$ não tiveram envolvimento em acidentes graves e 33\% tiveram. Uma das perguntas envolvia o tipo de freio utilizado durante a condução da motocicleta e $50 \%$ dos motoristas afirmaram utilizar os dois freios durante a condução. De acordo com as perguntas, mais $36 \%$ dos motociclistas afirmaram já terem conduzido embriagado e $60 \%$ afirmou dirigir desabilitado. Com isso, podemos deduzir que a maioria dos acidentes no trânsito são irresponsabilidade do próprio condutor, e falta de fiscalização dos órgãos competentes para essa função.

Além das perguntas objetivas, questionou os entrevistados sobre sugestões para melhoria no trânsito em Cuiabá. Dentre as respostas obtidas, destacam-se:

- Criação de faixas exclusivas para motocicletas;

- Melhora na sinalização das vias;

- Fiscalização mais atenta; e

- Conscientização e prudência maior por parte de todos os agentes do trânsito.

Quanto a respostas que cobraram do poder público se sobressaem as sugestões de melhor planejamento e espaçamento das vias.

\section{CONCLUSÃO}

O objetivo desse trabalho foi entrevistar pilotos de motocicletas entre os municípios de Cuiabá e Várzea Grande, e com isso traçar o perfil social de cada um, a forma de condução e o envolvimento em acidentes. Através dos dados obtidos foi possível se ter um parâmetro dos motoristas que já se envolveram em acidentes e revelar também as principais imprudências cometidas pelos mesmos no trânsito.

Por fim, ao analisar todas essas estatísticas percebe-se a necessidade de uma boa educação sobre trânsito, visto que a grande maioria dos acidentes são causados por uma conduta errônea do motorista/pedestre. Além de ser obrigação de todos inseridos no espaço público para uma convivência em sociedade ter conhecimento de educação no trânsito, esta ensina valores para a formação de um bom cidadão. 


\title{
Revista Científica ANAP Brasil
}

\author{
ISSN 1984-3240 - Volume 13, número 30, 2020
}

Alguns órgãos públicos como o Conselho Nacional de Trânsito (CONTRAN) e os Departamentos Estaduais de Trânsito (DETRAN) promovem campanhas educativas com o intuito de conscientizar a população sobre os riscos do trânsito para motoristas e pedestres que não seguem as normas vigentes, como não dirigir alcoolizado, usar o cinto de segurança, atravessar a rua na faixa de pedestres, etc.

Acredita-se que a educação de motoristas e pedestres associadas a um reforço de fiscalização e melhoria da infraestrutura são as principais medidas a serem tomadas visando abaixar as estatísticas apresentadas no tópico anterior. Ademais, investimentos para melhorar a iluminação e sinalização das ruas e avenidas, bem como a manutenção das vias públicas, devem ser feitas para diminuir os acidentes.

\section{AGRADECIMENTO}

Deixamos aqui o nosso agradecimento há alguns de nossos colaboradores, que foram fundamentais para a elaboração deste artigo. Começamos agradecendo especialmente ao Secretário Adjunto de Gestão e Planejamento Metropolitano - SAGPM Maurício Munhoz Ferraz por ter nos inspirado e nos dado um direcionamento sobre a execução deste artigo. E agradecer também o Graduando de Ciências Econômicas Matheus Antunio Canhete por participar ajudando tanto nas pesquisas científicas, como na elaboração do trabalho apresentado.

\section{REFERÊNCIAS BIBLIOGRÁFICAS}

BIFFE, Carina Rejane Fernandes et al. Perfil epidemiológico dos acidentes de trânsito em Marília. São Paulo, 2012*. Epidemiologia e Serviços de Saúde, [s.I.], v. 26, n. 2, p. 389-398, mar. 2017. Instituto Evandro Chagas. http://dx.doi.org/10.5123/s1679-49742017000200016.

COSTA, Ademir Araújo da. Crescimento Urbano e Problemas Socioespaciais: Um Estudo da Periferia de Natal. 4. N. rev. de Geografia da UFC: Ceará, 2003. 57-61 p.

CUIABÁ, Prefeitura Municipal. Programa Vida no Trânsito. Boletim Epidemiológico. Cuiabá, 2018.

FRANCO, Ayer et al. ANÁLISE DOS ÍNDICES DE ACIDENTES DE TRÂNSITO MEDIDOS AO LONGO DO TEMPO NA CIDADE DE RIO VERDE - GOIÁS. Faculdade Montes Belos, 2017. Disponível em:

$<$ http://faculdademontesbelos.com.br/wp-

content/uploads/2017/11/ANALISE_DOS_INDICES_DE_ACIDENTES_DE_TRANSITO_MEDIDOS_AO_LONGO_DO_TEM PO_NA_CIDADE_DE_RIO_VERDE.pdf>

MATO GROSSO, Secretaria de Estado de Segurança Pública. Departamento Estadual de Trânsito. Registro Nacional de Acidentes e Estatísticas de Trânsito. Cuiabá, 2019.

NORONHA, Cláudia Karine Carmo de; MORAIS, Eronice Ribeiro de. Ocorrência de óbitos por acidentes de motocicletas em Teresina, estado do Piauí, Brasil. 2. vol. 4. n. rev. Pan-Amazônica de Saúde, 2011. 11 p. 